\title{
Baccalaureate-educated Registered Nurses in nursing homes: Experiences and opinions of administrators and nursing staff
}

Citation for published version (APA):

Backhaus, R., Verbeek, H., van Rossum, E., Capezuti, E., \& Hamers, J. P. H. (2018). Baccalaureateeducated Registered Nurses in nursing homes: Experiences and opinions of administrators and nursing staff. Journal of Advanced Nursing, 74(1), 75-88. https://doi.org/10.1111/jan.13391

Document status and date:

Published: 01/01/2018

DOI:

10.1111/jan.13391

Document Version:

Publisher's PDF, also known as Version of record

\section{Document license:}

Taverne

Please check the document version of this publication:

- A submitted manuscript is the version of the article upon submission and before peer-review. There can be important differences between the submitted version and the official published version of record.

People interested in the research are advised to contact the author for the final version of the publication, or visit the DOI to the publisher's website.

- The final author version and the galley proof are versions of the publication after peer review.

- The final published version features the final layout of the paper including the volume, issue and page numbers.

Link to publication

\footnotetext{
General rights rights.

- You may freely distribute the URL identifying the publication in the public portal. please follow below link for the End User Agreement:

www.umlib.nl/taverne-license

Take down policy

If you believe that this document breaches copyright please contact us at:

repository@maastrichtuniversity.nl

providing details and we will investigate your claim.
}

Copyright and moral rights for the publications made accessible in the public portal are retained by the authors and/or other copyright owners and it is a condition of accessing publications that users recognise and abide by the legal requirements associated with these

- Users may download and print one copy of any publication from the public portal for the purpose of private study or research.

- You may not further distribute the material or use it for any profit-making activity or commercial gain

If the publication is distributed under the terms of Article $25 \mathrm{fa}$ of the Dutch Copyright Act, indicated by the "Taverne" license above, 


\title{
Baccalaureate-educated Registered Nurses in nursing homes: Experiences and opinions of administrators and nursing staff
}

\author{
Ramona Backhaus $^{1}$ (D) | Hilde Verbeek ${ }^{1}$ | Erik van Rossum ${ }^{1,2}$ | Elizabeth Capezuti ${ }^{3}$ | \\ Jan P.H. Hamers ${ }^{1}$
}

${ }^{1}$ Department of Health Services Research, CAPHRI, Care and Public Health Research Institute, Maastricht University, Maastricht, The Netherlands

${ }^{2}$ Research Centre for Community Care, Zuyd University of Applied Sciences, Heerlen, The Netherlands

${ }^{3}$ Hunter College and the Graduate Center, City University of New York, New York, NY, USA

\section{Correspondence}

Ramona Backhaus, Department of Health Services Research, CAPHRI, Care and Public Health Research Institute, Maastricht University, Maastricht, The Netherlands. Email: r.backhaus@maastrichtuniversity.nl

\section{Funding information}

This research project was funded by the Netherlands Organization for Health Research and Development (ZonMW, project number: 520001003). They had no involvement in the study design, data collection, data analysis, decision to publish, or the preparation of the manuscript.

\begin{abstract}
Aims: To understand how nursing homes employ baccalaureate-educated Registered Nurses (BRNs) and how they view the unique contributions of baccalaureateeducated Registered Nurses to staff and residents in their organizations.

Background: Although providing care for nursing home residents is complex and thus requires a high level of skills, organizations often struggle to recruit and retain BRNs. Some nursing home organizations do not employ baccalaureate-educated Registered Nurses at all. Among those that do, it is unknown how well these organizations make use of baccalaureate-educated Registered Nurses' expertise or if their roles are different from those of other staff.

Design: A qualitative study, consisting of 26 individual and three group interviews was conducted in the Netherlands.

Methods: Interviews were conducted at the board-, management- and staff-level in six nursing home organizations. Data were collected between January 2016-May 2016.

Results: Organizations employed baccalaureate-educated Registered Nurses to fulfil an informal leadership role for direct care teams. Organizations that do not employ baccalaureate-educated Registered Nurses were unable to articulate their role in the nursing home setting. Difficulties baccalaureate-educated Registered Nurses experienced during role implementation depended on role clarity, the term used to refer to the baccalaureate-educated Registered Nurse, the extent to which nurses received support, openness from direct care teams and baccalaureate-educated Registered Nurses' own behaviour. The unique contribution of baccalaureateeducated Registered Nurses perceived by respondents differed between and in organizations.
\end{abstract}

Conclusion: Our findings suggest that there is no "one size fits all" approach to employing baccalaureate-educated Registered Nurses in nursing homes. To ensure the satisfaction of both baccalaureate-educated Registered Nurses and the organizations that employ them, careful implementation and evaluation of their role is crucial.

\section{KEYWORDS}

elderly care, leadership, long-term care, nursing homes, quality of care, Registered Nurses, role implementation 


\section{INTRODUCTION}

Despite the heterogeneity in nursing homes worldwide (Sanford et al., 2015), there are common trends about care provision. Nursing homes will need to address a rising demand for services, more complex resident needs and an increase in patient flow in the near future. Additionally, working in nursing homes is becoming increasingly complex due to a focus on resident-centred care, technological innovations (e.g. robotic care, electronic monitoring systems) and the expectation for staff to partner with residents and their families throughout the care delivery process (Backhaus, Verbeek, Van Rossum, Capezuti, \& Hamers, 2015). Above all, nursing homes must ensure a high quality of care (QoC), an important component of which is the uptake of evidence-based practices (Boström, Slaughter, Chojecki, \& Estabrooks, 2012). Meeting these new demands while maintaining QoC requires capable, highly skilled direct care staff (Backhaus et al., 2015; Katz, 2011; Sloane, Zimmerman, \& D'Souza, 2014). Baccalaureate-educated Registered Nurses (BRNs) are educated with the critical thinking skills needed to tackle the challenge of complex resident care needs. Evidence from the hospital sector suggests that an increase in BRNs employed in hospitals leads to better QoC for patients (Aiken et al., 2014). However, for nursing homes, this relationship is less clear (Backhaus, Verbeek, Van Rossum, Capezuti, \& Hamers, 2014; Spilsbury, Hewitt, Stirk, \& Bowman, 2011). Recent research concluded that too few BRNs are working in Dutch nursing homes to ascertain a relationship with QoC (Hamers, Backhaus, Beerens, Van Rossum, \& Verbeek, 2016).

Difficulties in recruiting and retaining BRNs in nursing homes may be due to the low status and salary typically ascribed to those working in this setting (Eldh et al., 2015; Phelan \& McCormack, 2016). To guarantee sufficient staff to deliver around-the-clock direct care, some nursing home organizations opt to recruit a greater

TABLE 1 Direct nursing care staff in the Netherlands

\begin{tabular}{|c|c|c|c|}
\hline Type of staff & $\begin{array}{l}\text { Qualification } \\
\text { level }^{a}\end{array}$ & $\begin{array}{l}\text { Training } \\
\text { length } \\
\text { (in years) }\end{array}$ & Training offered at: \\
\hline $\begin{array}{l}\text { Baccalaureate- } \\
\text { educated } \\
\text { Registered Nurse }\end{array}$ & 6 & 4 & $\begin{array}{l}\text { University of } \\
\text { Applied Sciences }\end{array}$ \\
\hline $\begin{array}{l}\text { Vocationally trained } \\
\text { Registered Nurse }\end{array}$ & 4 & 4 & $\begin{array}{l}\text { Vocational Education } \\
\text { and Training (VET) } \\
\text { college }\end{array}$ \\
\hline $\begin{array}{l}\text { Certified nurse } \\
\text { assistant }\end{array}$ & 3 & $2-3$ & VET college \\
\hline Nurse assistant & 2 & 2 & VET college \\
\hline Nurse aide & 1 & $0.5-1$ & VET college \\
\hline
\end{tabular}

${ }^{a}$ According to Dutch qualification framework (NLQF) and European qualification framework (EQF). Traditionally, the educational level of baccalaureate-educated Registered Nurses was considered as level 5. According to the NLQF and EQF, level 5 refers to an associate degree. In the Netherlands, it is not possible to obtain an associate degree in the field of nursing. In Dutch nursing homes, most direct nursing care staff members are certified nurse assistants.

\section{Why is this research needed?}

- Although care of nursing home residents is complex and thus requires a high degree of skill, baccalaureate-educated Registered Nurses are a scarce resource in nursing homes.

- It remains unknown why some organizations succeed in recruiting and retaining baccalaureate-educated Registered Nurses in nursing homes, while other organizations do not.

- Little is known about how organizations hire baccalaureate-educated Registered Nurses, what is expected of them and what unique contribution of BRNs organizations experience.

\section{What are the key findings?}

- Organizations that employ baccalaureate-educated Registered Nurses viewed their role and positioning differently (i.e. as informal, clinical leaders) and were more easily able to attract them, than organizations that did not.

- There is a large variation in the positioning, roles, tasks and responsibilities expected of baccalaureate-educated Registered Nurses both within and between the organizations that employ them.

- Baccalaureate-educated Registered Nurses experienced difficulties related to role clarity, the term used to refer to their role, support from other employees, openness of direct care teams and their own behaviour.

\section{How should the findings be used to influence policy/practice/research/education?}

- Board members must be aware of the necessity of board-level leadership to implement the baccalaureateeducated Registered Nurses' role in nursing homes.

- As there is no "one size fits all" approach for employing baccalaureate-educated Registered Nurses in nursing homes, management must map out a strategy to determine how best to position them in their organizations.

- Organizations need to provide a clear vision of the responsibilities expected of baccalaureate-educated Registered Nurses prior to implementing the role in nursing homes.

number of lower educated (and therefore lower paid) staff. Table 1 provides an overview of direct nursing care staff in nursing homes. In the USA, recruiting lower educated staff has led to a high proportion of licensed practical/vocational nurses compared with Registered Nurses (RNs) in many nursing homes. In the Netherlands, more certified nurse assistants (CNAs) than RNs are employed in nursing 
homes, but these CNAs are comparable to the licensed practical/vocational nurses in the USA (Verkaik et al., 2011). As a result, the roles of BRNs and lower educated staff have become blurred and tasks are often allocated inappropriately, as was demonstrated in a recent study (Tuinman, De Greef, Krijnen, Nieweg, \& Roodbol, 2016). In organizations where BRNs have similar roles as CNAs, their expertise might become invisible (Phelan \& McCormack, 2016). If their unique contribution and expertise is not recognized in an organization, the ratios of BRNs might decrease even further, as lower level staff are seen as capable of fulfilling the same duties as the higher earning BRNs (Phelan \& McCormack, 2016). Therefore, it is important that the role of BRNs is differentiated from that of other professionals working in direct care (e.g. RNs, CNAs) and that each can work to their full scope of practice (McGilton et al., 2016).

\section{1 | Background}

Findings concerning the relationship between BRNs and QoC in nursing homes are inconsistent for three reasons (Backhaus et al., 2014; Spilsbury et al., 2011). First, compared with the hospital sector, few BRNs are working in direct resident care in the nursing homes and, in general, direct care staff in nursing homes tend to be less educated (Spilsbury et al., 2011). Although a specific educational programme was established at different universities of applied sciences throughout the Netherlands offering BRNs the opportunity to specialize in gerontology and geriatrics, BRNs remain scarce in Dutch nursing homes (Huizenga, Finnema, \& Roodbol, 2016). A recent study among 95 Dutch long-term care facilities indicated that BRNs were employed in only half of 282 participating wards (Backhaus et al., 2017). Second, research has yet to confirm whether nursing homes that do employ BRNs make use of their expertise, or differentiate their roles from those of other staff members such as nursing home medical specialists, speech therapists, physiotherapists and psychologists (Huls, De Rooij, Diepstraten, Koopmans, \& Helmich, 2015). Third, a BRN who is employed in a nursing home typically works across several different wards, meaning that the time he or she spends in any one ward is often low (Backhaus et al., 2017). The relationship between QoC and BRN employment could be mediated by this practice of assigning BRNs to too wide a range of wards. Therefore, more information is needed regarding the ways nursing home organizations employ BRNs and what unique contribution they perceive their work to have for resident care and the organization as a whole. Insights into the successful recruitment and retention of BRNs in some organizations may also help explain why other organizations hesitate to employ, or are unable to attract, BRNs.

\section{2 | THE STUDY}

\subsection{Aim}

To understand how nursing homes employed BRNs and how they viewed the unique contributions of BRNs for staff and residents in their organizations. To address this aim, we asked three research questions:

1. How are BRNs employed as professional leaders in nursing homes?

2. How did administrators and staff of nursing home organizations perceive the implementation of the BRN role?

3. What are nursing home administrators and staff perceptions about BRNs' care practices?

\section{2 | Design}

Qualitative interviews (semi-structured, face-to-face individual or group interviews) were conducted between January 2016 - May 2016 (Polit \& Beck, 2017).

\section{3 | Participants}

Participants were from six nursing home organizations in the Netherlands. Nursing homes in the Netherlands provide long-term residential care for individuals with dementia (referred to as psychogeriatric) or physical disabilities (referred to as somatic), and short-term skilled care for rehabilitation of subacute conditions (Huls et al., 2015). We used purposive sampling to select participants who were expected to provide particularly rich information (Polit \& Beck, 2017). Participants were drawn from two "types" of organizations; those nationally regarded as on the forefront of employing BRNs in their nursing homes (organizations $\mathrm{A}-\mathrm{C}$ ) and those that were shown in a previous study to have no or very few BRNs employed in their nursing homes (organizations D-F). To ensure that the collected data represented a range of perspectives, we aimed to include participants from different organizational levels (see Table 2). Two organizations (organizations B and F) proposed to interview a nursing home director as well, as they were expected to provide richer information on the research topic. In a third organization (organization D), the director participated instead of a board member.

\subsection{Data collection}

Data were collected via semi-structured, face-to-face individual or group interviews conducted between January 2016 - May 2016. Board members, directors, ward/nursing home managers and BRNs were interviewed individually, while direct care staff members participated in group interviews. A topic list was used to structure the interviews (Table 3). All interviews were conducted by the primary author and were audiotaped. Board members, directors, managers and BRNs were interviewed individually, while direct care staff members participated in group interviews. Interviews were held in a quiet room in the nursing homes. During individual interviews, only the respondent and the primary author were present. During group interviews, a second researcher was present to take notes and to verify that all interview topics were covered. 
TABLE 2 Interviewed participants per organization

\begin{tabular}{|c|c|c|}
\hline Organization & $\begin{array}{l}\text { Interviewed participants } \\
\text { per organization }\end{array}$ & $\begin{array}{l}\text { Respondent } \\
\text { number(s) }\end{array}$ \\
\hline \multirow[t]{8}{*}{ Organization A } & Individual interviews: & \\
\hline & One board member & 4 \\
\hline & Two ward managers & 5,6 \\
\hline & Two BRNs & 12,13 \\
\hline & Group interview: & \\
\hline & Two vocationally trained RNs & 7,8 \\
\hline & One CNA & 9 \\
\hline & Two nurse assistants & 10,11 \\
\hline \multirow[t]{8}{*}{ Organization B } & Individual interviews: & \\
\hline & One board member & 22 \\
\hline & One director & 21 \\
\hline & Two ward managers & 23,24 \\
\hline & Two BRNs & 30,31 \\
\hline & Group interview: & \\
\hline & Four CNAs & $25,26,27,28$ \\
\hline & One nurse assistant & 29 \\
\hline \multirow[t]{8}{*}{ Organization C } & Individual interviews: & \\
\hline & One board member & 32 \\
\hline & Two nursing home managers & 33,34 \\
\hline & Two BRNs & 39,40 \\
\hline & Group interview: & \\
\hline & One vocationally trained $\mathrm{RN}$ & 35 \\
\hline & One CNA & 36 \\
\hline & Two nurse assistants & 37,38 \\
\hline \multirow[t]{3}{*}{ Organization D } & Individual interviews: & \\
\hline & One director & 1 \\
\hline & Two ward managers & 2,3 \\
\hline \multirow[t]{3}{*}{ Organization E } & Individual interviews: & \\
\hline & One board member & 19 \\
\hline & Two ward managers & 18,20 \\
\hline \multirow[t]{4}{*}{ Organization F } & Individual interviews: & \\
\hline & One board member & 14 \\
\hline & One director & 17 \\
\hline & Two nursing home managers & 15,16 \\
\hline
\end{tabular}

BRN: baccalaureate-educated Registered Nurse; RN: Registered Nurse; CNA: certified nurse assistant.

\subsection{Ethical considerations}

According to Dutch law, approval from an ethics committee was not needed, as no patients were involved and data collection was not burdensome (http://www.ccmo.nl/en/your-research-does-it-fall-underthe-wmo). Oral consent for participation and audiotaping was obtained prior to all interviews. At the start of each interview, the interviewer emphasized that participating in the (group) interview was voluntary and that answers were treated strictly confidential. Respondents were able to withdraw at any time. Data were analysed anonymously.
TABLE 3 Interview topic list

\begin{tabular}{|c|c|c|}
\hline & $\begin{array}{l}\text { Organizations that } \\
\text { employ BRNs in } \\
\text { nursing homes }\end{array}$ & $\begin{array}{l}\text { Organizations that } \\
\text { do not or hesitate } \\
\text { to employ BRNs in } \\
\text { nursing homes }\end{array}$ \\
\hline \multicolumn{3}{|l|}{ Board members and directors } \\
\hline $\begin{array}{l}\text { Vision of the employment } \\
\text { of BRNs in nursing homes }\end{array}$ & $\nu$ & $\nu$ \\
\hline $\begin{array}{l}\text { Experienced added value } \\
\text { of BRNs in nursing homes }\end{array}$ & $\nu$ & - \\
\hline \multicolumn{3}{|l|}{ Ward/nursing home managers } \\
\hline $\begin{array}{l}\text { Vision of the employment } \\
\text { of BRNs in nursing homes }\end{array}$ & 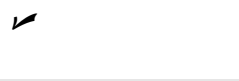 & 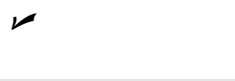 \\
\hline $\begin{array}{l}\text { Positioning of BRNs } \\
\text { in nursing homes }\end{array}$ & $\swarrow$ & - \\
\hline $\begin{array}{l}\text { Implementation of BRN role } \\
\text { in nursing homes }\end{array}$ & $\nu$ & - \\
\hline $\begin{array}{l}\text { Experienced added value } \\
\text { of BRNs in nursing homes }\end{array}$ & $\nu$ & - \\
\hline \multicolumn{3}{|l|}{ Direct care staff members } \\
\hline $\begin{array}{l}\text { Experienced added value } \\
\text { of BRNs in nursing homes }\end{array}$ & $\swarrow$ & - \\
\hline \multicolumn{3}{|l|}{ BRNs } \\
\hline $\begin{array}{l}\text { Positioning of BRNs in } \\
\text { nursing homes }\end{array}$ & $\swarrow$ & - \\
\hline $\begin{array}{l}\text { Implementation of BRN role } \\
\text { in nursing homes }\end{array}$ & $\swarrow$ & - \\
\hline $\begin{array}{l}\text { Experienced added value } \\
\text { of BRNs in nursing homes }\end{array}$ & 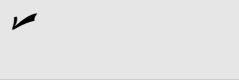 & - \\
\hline
\end{tabular}

BRN: baccalaureate-educated Registered Nurse

\section{6 | Data analysis}

All interviews were transcribed verbatim by the primary author. Transcripts were read twice each before being analysed using directed content analysis (Hsieh \& Shannon, 2005). The primary author selected four interviews to analyse using a four-step approach that would determine the codes for the remaining transcripts. First, the text of all four transcripts was divided into "meaning units" (Graneheim \& Lundman, 2004). Meaning units could consist of one or more sentence(s) or entire paragraphs of a transcript. Second, all meaning units were condensed into short descriptions of the text (manifest content) and, when possible, interpretations of their underlying meanings (latent content) were documented (Graneheim \& Lundman, 2004). Third, the condensed meaning units were coded. Topics from the topic list were used as basis for the initial codes (Utens, Dirksen, Van der Weijden, \& Joore, 2016). Text passages that could not be coded with the initial codes were given a new code. In the final step, depending on the breadth of a code, subsequent analyses were conducted to identify subcodes (Hsieh \& Shannon, 2005; Utens et al., 2016). To ensure quality of the analysis, two members of the research team separately analysed these same four interviews using the same 
four-step approach. Their analyses were compared with those of the primary author. Consensus on small differences in the condensed meaning units and in coding was reached through discussion. It was concluded that the codes did not need to be changed. After that, all other interviews were analysed by the primary author and analyses were discussed with the research team. Based on the analyses of all interviews, the research team concluded that data saturation was reached, as no new themes were identified in the data.

\section{7 | Study rigour}

To enhance the quality and integrity of our study, different strategies were applied. Purposive sampling enabled us to continuously compare the views of different respondent groups (e.g. board members, direct care staff) during the data analysis and to illuminate differences between groups (Barbour, 2001). Person and space triangulation led to more complete insights into the issues under study. Person triangulation refers to the collection of data from different respondent groups, aimed at validating data by including multiple perspectives (Polit \& Beck, 2017). Space triangulation refers to collecting data at multiple sites to test for cross-site consistency (Polit \& Beck, 2017). Cross checking of the coding process by members of the research team led to a further refinement of the coding frame (Barbour, 2001).

\section{FINDINGS}

In this study, 26 individual interviews and three group interviews (with 14 participants in total) were held with staff members from six nursing home organizations. Table 4 provides insights into respondents' demographic and occupational characteristics. Table 5 presents examples of quotes that support our findings.

\subsection{Employing BRNs as professional leaders in nursing homes}

Interview data showed that, within and between organizations that employ BRNs in their nursing homes, there was great variation in the positioning, roles, tasks and responsibilities of BRNs (see Table 6). For example, BRNs held formal positions in a direct care team or, instead, were positioned in addition to the teams (as institutional-level consultants). BRNs were also expected to improve QoC in two different ways: some were instructed to focus on their specific areas of expertise (e.g. resident behaviour), while others sought to improve QoC in general.

Although all board members shared the opinion that BRNs have a unique contribution to care practices in nursing homes, not all organizations actively employed them. Organizations that did employ BRNs differed in their vision of how to position the BRNs in nursing homes, took responsibility for employing them and reported fewer problems enticing them to work in their nursing homes.
TABLE 4 Respondents' characteristics

\begin{tabular}{|c|c|c|}
\hline & $\begin{array}{l}\text { Organizations that } \\
\text { employ BRNs in } \\
\text { nursing homes }\end{array}$ & $\begin{array}{l}\text { Organizations } \\
\text { that do not or } \\
\text { hesitate to } \\
\text { employ BRNs in } \\
\text { nursing homes }\end{array}$ \\
\hline $\begin{array}{l}\text { Board members and } \\
\text { directors }(n=8)\end{array}$ & $(n=4)$ & $(n=4)$ \\
\hline Age (mean/range) & $58(55-64)$ & $55(43-60)$ \\
\hline Gender: Female & 2 & 2 \\
\hline $\begin{array}{l}\text { Years of experience in current } \\
\text { position (mean/range) }\end{array}$ & $12(8-17)$ & $3(0-8)$ \\
\hline RN background (Yes) & 3 & 1 \\
\hline $\begin{array}{l}\text { Ward/nursing home } \\
\text { managers }(n=12)\end{array}$ & $(n=6)$ & $(n=6)$ \\
\hline Age (mean/range) & $53(43-59)$ & $49(42-56)$ \\
\hline Gender: Female & 4 & 5 \\
\hline $\begin{array}{l}\text { Years of experience in current } \\
\text { position (mean/range) }\end{array}$ & $9(0-24)$ & $4(0-16)$ \\
\hline RN background (Yes) & 6 & 3 \\
\hline $\begin{array}{l}\text { Direct care staff } \\
\text { members }(n=14)\end{array}$ & $(n=14)$ & \\
\hline Vocationally trained $\mathrm{RNs}$ & 3 & \\
\hline CNAs & 6 & \\
\hline Nurse assistants & 5 & \\
\hline Age (mean/range) & $41(25-62)$ & \\
\hline Gender: Female & 14 & \\
\hline $\begin{array}{l}\text { Years of experience in current } \\
\text { position (mean/range) }\end{array}$ & $13(0-31)$ & \\
\hline BRNs $(n=6)$ & $(n=6)$ & \\
\hline Age (mean/range) & $39(30-49)$ & \\
\hline Gender: Female & 6 & \\
\hline $\begin{array}{l}\text { Years of experience in current } \\
\text { position (mean/range) }\end{array}$ & $3(2-7)$ & \\
\hline
\end{tabular}

BRN: baccalaureate-educated Registered Nurse; RN: Registered Nurse; CNA: certified nurse assistant.

\subsection{1 | Having a vision of the BRN role in nursing homes}

Board members of organizations that employ BRNs had a vision of how to use their skills to improve QoC. At the ward level, they expected BRNs to fulfil an informal, clinical leadership role for direct care teams, serving as role models for direct care staff and helping teams to implement care innovations (e.g. electronic resident record). At the organizational level, BRNs were expected to advise managers, participate in working groups or represent their organization in external meetings. All three board members preferred employing BRNs that received specialized training in gerontology and geriatrics. They mentioned that having a vision for BRNs in nursing homes is crucial for their successful employment.

Board members of organizations that do not employ BRNs did not have a vision of how they might use them in their nursing homes and could not describe how they would employ them in their organization. 
TABLE 5 Examples of quotes documenting our findings

\begin{tabular}{ll} 
Theme & Subtheme \\
\hline $\begin{array}{l}\text { Employing BRNs as } \\
\text { professional leaders in }\end{array}$ & Having a vision \\
nursing homes & of BRNs in \\
& nursing homes
\end{tabular}

Taking responsibility and making room for employing BRNs in nursing homes

\section{Example quote(s)}

They are educated at bachelor's level, so that means they can look at care delivery from a distance. And they also have the specialization in geriatrics and gerontology. So yes, they can provide advice about the care of an individual, but are also very good care process wise, the CanMeds roles, which is their added value. So, in my opinion, they improve the overall quality of the team.

(Board member, organization C, respondent 32)

The philosophy was that you actually have people engaged in policy development, but doing that from practical experience and not behind an office desk.

(Board member, organization B, respondent 22)

I think at a certain point, we just have to say, 'Well, we're just going to recruit BRNs again' and then give those people the possibility to show where they can excel and what their unique contribution is.

(Board member, organization E, respondent 19)

It was really left to the responsibility of the nursing home managers. And what you saw was, because of budgetary considerations, it sure was easy to choose for a lower level of expertise.

(Board member, organization E, respondent 19)

But you should also facilitate it by saying 'Well guys, nice to hire people, but other people have to go.' They should really take steps as Board of Directors. As a nursing home manager, I may have to say more often 'Guys, do we want that? Great, welcome! But then we also have to act, maybe fire people, terminate contracts, or shape it differently.' It's all well and good to say those things, but I think it should be better facilitated.

(Nursing home manager, organization F, respondent 15)

I think we are very focused on vocationally-trained RNs, but not yet on BRNs. At the moment there is a selection procedure for staff members who want to become a vocationally-trained RN. For internal people. And then you already see: there are only 20 spots and more than 60 people applied. So I think that the demand for a training to become a BRN would be there.

(Ward manager, organization $E$, respondent 18)

Attracting BRNs to work in nursing homes
Nursing homes are not challenging enough for graduated BRNs of the age of 20 or 25 . It remind it from myself. Young BRNs want a lot more action.

(Ward manager, organization $E$, respondent 20)
Implementing the

$\mathrm{BRN}$ role
Role clarity

I thought that the position was already implemented in the organization. At the beginning it was very difficult to collaborate with the psychologists, because they felt threatened in their area of expertise. They felt like, 'This is part of our field,' which it is. And then I said, 'You have your work, but I can help you, shall we take a look at it?' And then you notice that you got a lot more cooperation because you are much less threatening.

(BRN, organization A, respondent 12) 
TABLE 5 (Continued)

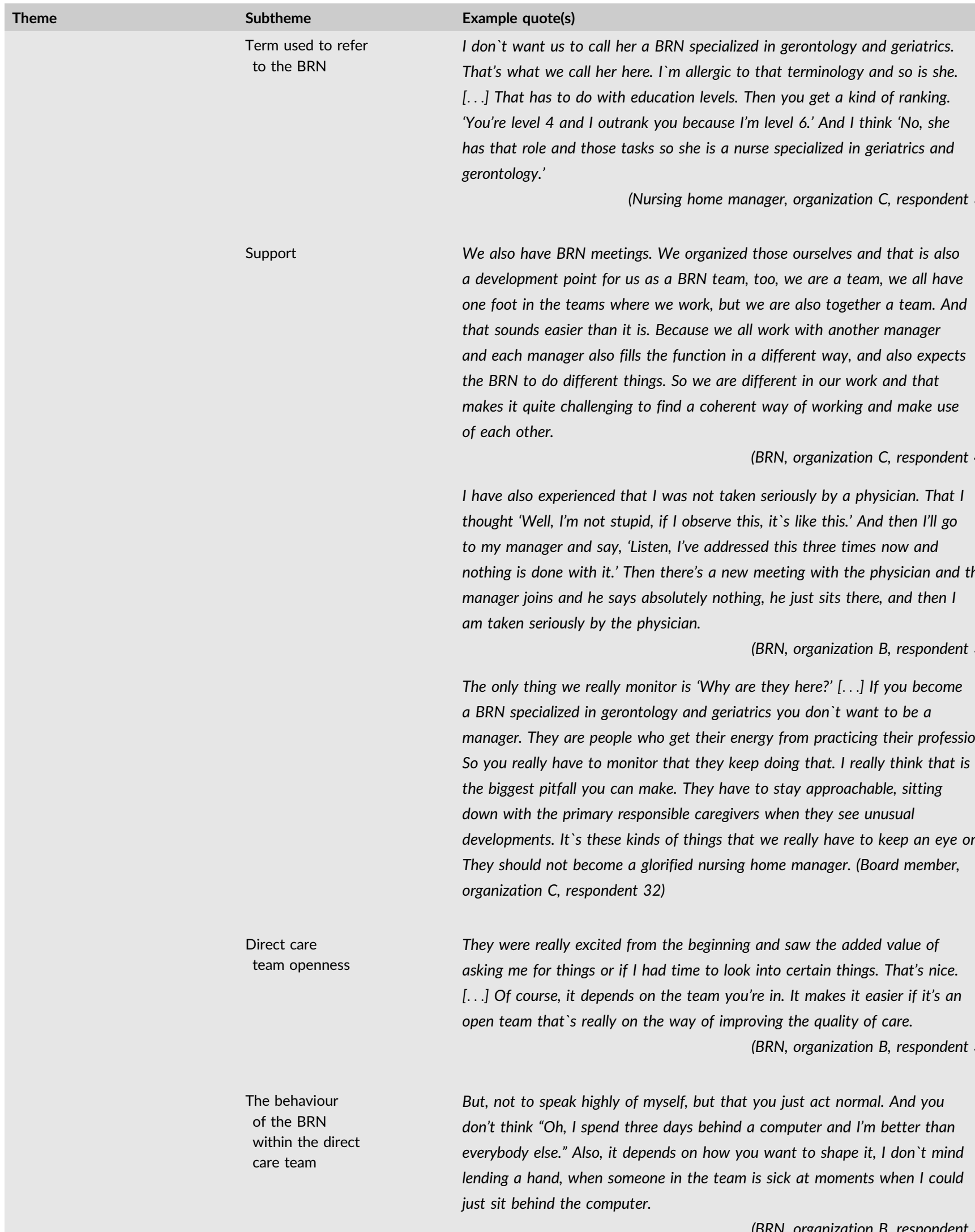

(BRN, organization $B$, respondent 30) 


\section{TABLE 5 (Continued)}

\begin{tabular}{|c|c|c|}
\hline \multirow[t]{3}{*}{ Theme } & Subtheme & Example quote(s) \\
\hline & & $\begin{array}{l}\text { I guard against the superiority. The role is different, but I don't want the } \\
\text { other staff members saying 'Well that's a BRN, she has to do that and that.' } \\
\text { No, she is part of the team. }\end{array}$ \\
\hline & & (Ward manager, organization B, respondent 24 \\
\hline $\begin{array}{l}\text { Perceived unique } \\
\text { contribution of } \\
\text { BRNs in care } \\
\text { practice }\end{array}$ & $\begin{array}{l}\text { Experiences of } \\
\text { board members, } \\
\text { directors and } \\
\text { ward/nursing } \\
\text { home managers }\end{array}$ & $\begin{array}{l}\text { Behavioral problems, for example of residents with dementia, I see that direct } \\
\text { care staff finds it difficult. For example, the interaction and group process, if } \\
\text { a resident walks around a lot, how do you deal with this in a small-scale } \\
\text { setting? And then you really see the added value of the BRN specialized in } \\
\text { gerontology and geriatrics. She assesses 'What have we tried? What kind of } \\
\text { policy? What is effective? What are our measuring instruments? How do we } \\
\text { analyze this?' Basically the red line through the whole care process. }\end{array}$ \\
\hline
\end{tabular}

(Nursing home manager, organization $C$, respondent 33)

At the same time, I see that the sickness absence rate goes down since they are working here. We have a sickness absence rate of less than 5 percent, which no one else has. For years we were number one because of the low sickness absence rate. That's also their merit because they make the struggles that those girls have to deal with every day more bearable. If you have a resident who claims 24/7, you're happy if someone comes and really helps you.

(Board member, organization A, respondent 4)

Experiences of direct care staff members
The management told us that BRNs were coming to provide more depth, making action plans on how to better handle things here, look into verbal agitation of residents, into how we can make sure that residents move more. They told all that, but that's not happening right now.'

(CNA, organization $B$, respondent 25)

BRN: baccalaureate-educated Registered Nurse; RN: Registered Nurse; CNA: certified nurse assistant.

\subsection{2 | Taking responsibility and making room for employing BRNs in nursing homes}

In organizations that did not employ BRNs, nobody felt primarily responsible for recruiting BRNs. Board members and managers felt partially responsible, but, at the same time, board members felt that managers should take more responsibility (and vice versa). Board members stressed the lack of specific guidelines on this issue and concluded that the decision to employ BRNs in nursing homes ultimately rested with the managers. According to board members, managers often opted to hire lower educated staff who could be paid less. At the same time, managers felt that the board members did not adequately support employment of BRNs in their nursing homes. For example, the managers highlighted that the board members did not facilitate additional education so that their vocationally trained RNs could become BRNs.

In one organization that does not regularly employ BRNs, respondents felt that it was difficult to "make room" for more highly educated staff. In contrast, in the organizations that do employ
BRNs, board members felt that it was their responsibility to actively facilitate the employment of BRNs:

By indicating that I find it important and stand behind it. Despite self-organizing teams, to outline several guidelines and to say: 'Still, I want to see that at least in every ward one or two baccalaureate-educated people are walking around.' [...] Or through giving our people the opportunity to follow a BRN educational program facilitated by the company.

(Board member, organization B, respondent 22)

\subsubsection{Attracting BRNs to work in nursing homes}

The organizations that employ BRNs did not report any problems regarding recruiting or retaining them. In contrast, board members in organizations that did not employ BRNs mentioned that they experienced difficulties attracting BRNs to work in their nursing homes. 
TABLE 6 Employment of BRNs in somatic and psychogeriatric nursing home wards

\begin{tabular}{|c|c|c|c|}
\hline & Organization A & Organization B & Organization C \\
\hline Positioning & $\begin{array}{l}\text { In addition to the direct care } \\
\text { teams (consultant role) } \\
\text { Work with more than } \\
\text { one team }\end{array}$ & $\begin{array}{l}\text { Formally part of and work within one } \\
\text { direct care team } \\
\text { Work } 50-60 \% \text { of their time in direct } \\
\text { care, while } 100 \% \text { employed in direct } \\
\text { care team }\end{array}$ & $\begin{array}{l}\text { In addition to the direct care teams } \\
\text { (consultant role) } \\
\text { Work together with more than one team } \\
\text { Closely collaborate with nursing home } \\
\text { managers and primary responsible } \\
\text { caregivers }\end{array}$ \\
\hline $\begin{array}{l}\text { Role in direct } \\
\text { resident care }\end{array}$ & $\begin{array}{l}\text { Decide themselves on the } \\
\text { tasks and time they spend } \\
\text { in direct care }\end{array}$ & $\begin{array}{l}\text { Fulfil the same tasks as other team members } \\
\text { Tasks can be related not only to basic care } \\
\text { (e.g. bathing and dressing) but also to } \\
\text { reserved procedures (e.g. catheterization) } \\
\text { In addition: expected to make a difference in } \\
\text { care through overviewing the whole care } \\
\text { process within their ward (e.g. by } \\
\text { coordinating the team and discussing things } \\
\text { that could be improved) }\end{array}$ & $\begin{array}{l}\text { Tasks and time spent in direct care } \\
\text { depend, to a great extent, on how a } \\
\text { nursing home manager (in deliberation } \\
\text { with the BRN) fills in the BRN role }\end{array}$ \\
\hline $\begin{array}{l}\text { Tasks and responsibilities } \\
\text { exceeding direct care }\end{array}$ & $\begin{array}{l}\text { Are employed for specific } \\
\text { expertise areas, that is, } \\
\text { problematic behaviour } \\
\text { of residents, emotion- } \\
\text { oriented care and pain. } \\
\text { Some give advice to general } \\
\text { practitioners in the } \\
\text { community care setting (on } \\
\text { how to deal with } \\
\text { problematic behaviour) }\end{array}$ & $\begin{array}{l}\text { Receive overarching assignments and } \\
\text { responsibilities (e.g. educating other staff } \\
\text { members, participating in expert groups on, } \\
\text { for example, restraint-free care) from the } \\
\text { director as soon as they are familiar with all } \\
\text { routines and procedures in their ward } \\
\text { Each BRN develops her own area of } \\
\text { expertise (e.g. antipsychotic drug use) which } \\
\text { is used on the nursing home and } \\
\text { organizational levels }\end{array}$ & $\begin{array}{l}\text { Primarily responsible for observing and } \\
\text { coaching several teams to improve QoC } \\
\text { Choice on which quality aspects to } \\
\text { focus on depends on the quality of a } \\
\text { team and what the BRNs (and/or the } \\
\text { nursing home managers) find important } \\
\text { (e.g. reducing medication incidents, } \\
\text { coaching teams on how and what to } \\
\text { report in a resident care plan) }\end{array}$ \\
\hline
\end{tabular}

For example, they reported that students who did their internships in the organization preferred to work in a hospital after graduation. Most of the managers from organizations that do not employ BRNs believed the work in somatic or psychogeriatric long-term nursing home wards lacks the complexity needed to attract BRNs.

\section{2 | Implementing the BRN role}

Most interviewed BRNs experienced difficulties when they started working in the nursing home where they were employed. These difficulties were related to role clarity, the term used to refer to the BRN, the extent to which they received support, the openness of the direct care teams and how they were expected to work in the nursing team.

\subsection{1 | Role clarity}

As the BRN role was a new one in the participating organizations, clear job descriptions were lacking. Most BRNs stressed that, especially in the beginning, they missed guidelines on how they should perform their role:

Sometimes I still have the feeling: 'Gosh, provide me with some guidelines. Am I now doing the work of a policy employee or a manager? Am I doing my work well?'

(BRN, organization C, respondent 39)

Board members in organizations that employed BRNs agreed that role clarity was a prerequisite for the successful implementation of the BRN role in nursing homes. In their organizations, the roles and tasks BRNs fulfilled were differentiated from those of other staff members. BRN role clarity received continuous attention from the board members. Despite this attention, some of the BRNs felt they had to overcome resistance and win trust from coworkers, who believed the BRNs were taking over part of their role.

\subsection{2 | Terminology associated with BRNs}

In two organizations, respondents talked about "BRNs" or "BRNGGs" (referring to a BRN specialized in gerontology and geriatrics). In one organization, respondents used the term "behaviour nurse" (i.e. a nurse that focuses on challenging dementia-related behaviour) when talking about the BRNs. According to some respondents, referring to a BRN as "the BRN" might be problematic, as it could establish an unnecessary sense of hierarchy. In contrast, referring to a "behaviour nurse" provides more information about their specific role in the organization. Thus, some respondents stressed that the term used to refer to BRNs can help make their role clearer.

\subsection{3 | Support}

Most interviewed BRNs mentioned that, especially in the beginning, they felt it was important to have the opportunity to talk with other BRNs. In all organizations, BRNs working in nursing homes had close contact with one another. In one organization, the BRNs had formal meetings where they could discuss the challenges they were encountering. 
Moreover, BRNs reported that it was helpful to discuss difficulties with their managers. Similarly, the interviewed managers felt that it was important to support the BRNs:

It took some time before it was clear for us what the BRN was going to do. But one of the conditions, for me, was also that I sat together with her every week, like: 'Okay, what are you doing at the moment?' requires also a bit of coaching from me towards her, I find that important.

(Nursing home manager, organization C, respondent 34)

Nevertheless, the interviewed managers felt that not all managers in their organization were open to the employment of BRNs in their wards/nursing homes:

You can see that managers agree with it or not. [...] Because you will come very close into such a team and in the beginning, there was also resistance. [...] Because you get an inside look. And not everyone is open for that. Because sometimes you just have your things not properly regulated.

(Ward manager, organization A, respondent 5)

\subsection{4 | Direct care team openness}

Whether or not BRNs experienced difficulties when they started working in their nursing homes also depended on the openness of their team. Teams that were open to change and were committed to improving QoC were not resistant to the addition of BRNs.

\subsubsection{The behaviour of the BRN in the direct care team}

Some BRNs mentioned that the direct care staff they worked with should not get the feeling that the BRNs stood "above" them and BRNs had to make efforts to be viewed as part of the team:

I have worked in direct resident care [...] and someone said: 'But you are the 'behavior consultant.' And I said: 'But I am also a nurse and I will stay being a nurse at all times.' And then you notice that barriers disappear, because you are one of them, thus you will have much easier access. [. . . I find it very important that the BRN does not think: " am the BRN, I do my coordination tasks and you wash the residents and I tell you what you have to do.' I think working in direct resident care is not a low-level task. As a nurse, that is part of your job. And I also like to do it.

(BRN, organization A, respondent 12)

Some of the interviewed managers said that it is the role of a manager to monitor the BRN and ensure he or she does not attain a "better" position in the direct care teams.

\subsection{Perceived unique contribution of BRNs in care practice}

The unique contribution of BRNs perceived by board- and management-level respondents differed from the experiences of direct care staff.

\subsubsection{Experiences of board members, directors and ward/nursing home managers}

Board- and management-level respondents unanimously stressed that BRNs had a unique contribution for their nursing homes. Depending on how the BRNs were positioned, the perceived unique contribution differed. In all organizations, respondents felt that the employment of BRNs was of unique contribution for the way care was delivered and that BRNs had positive effects on residents and other employees. Respondents felt that employing a BRN who serves as a coach for direct care teams and is consistently present in the ward improved the delivery of care. Having a BRN fill this coaching role meant that issues in the ward could be discussed, reflected on and directly addressed.

Depending on how the BRNs were positioned in the nursing homes, board members and managers mentioned a range of positive resident outcomes, such as a decrease in the use of physical restraints. However, resident-level outcomes were not always easily measurable, as they demand conscious reflection on the BRN's way of working. For example, it was difficult to measure the effect of BRNs on client-centredness:

The effect it has when the BRN and direct care staff members look together at the client: 'What do you see? What do I see?' and that you talk about it. Taking five minutes of your time for that. To ask a client: 'I give you every morning black coffee, do you actually like that?' This effect has been enormous and has really given a boost to client-centeredness.

(Board member, organization A, respondent 4)

On the employee level, board members from two organizations stressed that employing BRNs led to higher satisfaction among direct care staff. In one organization, it was added that the higher satisfaction led to a decrease in absenteeism. Different respondents had experienced that BRNs helped direct care staff to cope with the daily challenges they experience in their practice.

\subsection{2 | Experiences of direct care staff members}

When BRNs were employed in specific areas of expertise (i.e. problematic resident behaviour, pain), the interviewed staff members who worked in psychogeriatric wards were very satisfied with the BRNs and perceived their unique contribution:

Since we have her, I see changes in our ward, in the sense: we ourselves already take care of a good observation, but 
also through being more alert before calling in the behavior nurse. Or regarding pain, to, for example, already complete a pain-score list for a few days that we can hand over 'Look, this is what we have already seen.'

(Vocationally trained $R N$, organization A, respondent 8)

In somatic wards of this organization, BRNs were seldom contacted for advice, as direct care staff considered their expertise (i.e. resident behaviour, emotion-oriented care, pain) as less relevant for a somatic ward.

In the other two organizations, respondents were less positive. In organization B, where BRNs are part of one direct care team, respondents reported that they did not experience any unique contribution of the BRNs. The interviewed direct care staff members said they did not see the BRNs fulfilling the coordinating role they are expected to hold when working in direct resident care. However, they stressed that the unique contribution of a BRN might depend on the individual BRN themselves:

But we have one BRN here, working in another ward, she is great. She also gives training sessions and does a lot of extra things. She also travels the whole country to see 'What is going on within your organization? What can we improve?' [...] I am sure that she has a unique contribution.

(CNA, organization $B$, respondent 25)

In organization $\mathrm{C}$, the interviewed respondents worked in a nursing home that was taken over from a bankrupt organization half a year ago. There, the BRN role was new and respondents mentioned that they did not experience any unique contribution of the BRNs since their role had not been made clear. These respondents stressed that their experiences might not be representative of those of other staff in the organization, as the role of BRNs had been further developed in other nursing homes in their organization.

\section{DISCUSSION}

This study found that having a vision of how to use BRNs in nursing homes is a key factor in determining whether or not an organization employs BRNs in their nursing homes. Organizations that do not employ BRNs assume that BRNs do not want to work in nursing homes, while organizations that have a clear vision of how to implement their role are successful in employing and retaining BRNs. In organizations that employ BRNs, the percentage of board members and managers with an RN background was higher. Within and between organizations that employ BRNs, there is great variation in their positioning, roles, tasks and responsibilities. Difficulties BRNs experienced when they started working in the nursing homes were related to their role clarity, the terminology used to refer to the BRN, the extent to which they received support, the openness of the direct care teams and their own behaviour. The unique contribution of BRNs perceived by direct care staff members differed between organizations.

Without clear guidelines from professional organizations and academic institutions to prepare BRNs for nursing home practice, individual organizations are left to independently determine how to employ BRNs in their organizations. The findings of this study suggest that the employment of BRNs in nursing homes requires boardlevel leadership, as board members are expected to have a vision of how to use BRNs in the organization and to actively facilitate their employment. In organizations lacking that vision, the role of the BRN is not distinguished from the roles of other staff. This helps to explain why these organizations experienced difficulties in attracting and retaining BRNs. None of the organizations that had a clear vision of how to employ BRNs experienced these difficulties.

Even though our findings indicate that there is no "gold standard" for employing BRNs in nursing homes, they suggest different macro-, meso- and micro-level factors that could be considered when implementing the BRN role in nursing homes worldwide. On a macro-level, role clarity was considered a prerequisite for the successful implementation of the BRN in the nursing home, which is closely related to having a vision of how to employ BRNs. McAiney et al. (2008), who evaluated a practice model for nurse practitioners (NPs) in long-term care homes, concluded that role clarity facilitated the implementation of the NP role, as it increased staff members' awareness of the knowledge and skills of NPs and led to better support from staff members. Respondents in our study stressed that it is necessary to inform and prepare staff members at all levels in the organization before implementing the BRN role, while paying attention to how the role is framed. Findings from McAiney et al. (2008) confirm that staff members should be engaged in the process of identifying the role that BRNs should fulfil in the organization before the BRN begins working there, as this process made the actual implementation of the NP role more successful in their study. Hospitals' experiences with implementing advanced practice nurse (APN) roles similarly suggest that, in organizations, consensus on role attributes (i.e. role scope, goals, core competencies, educational requirements) should be reached prior to role implementation (Jokiniemi, Haatainen, \& Pietilä, 2015).

On a meso-level, BRNs in our study reported that they considered the support and openness of managers, direct care teams and other BRNs to be important, as they expected a degree of resistance from other staff. Given the additional educational preparation in geriatrics and their role as consultants to other nurses and clinicians, the BRN role can be compared with the APN role in nursing homes. Barriers to the development of APN roles include physician resistance (Fougère et al., 2016). Moreover, managers who were supportive when implementing the APN role, while at the same time trusting the APN and supporting them in implementing their role autonomously, were considered crucial for APN role achievement (Jokiniemi et al., 2015). Our results similarly suggest that support and openness of managers and direct care teams regarding BRNs is an essential first step towards reducing resistance to their employment. In a recent study on BRNs who specialize in gerontology and geriatrics, Huizenga et al. (2016) concluded that these BRNs are pioneers who have few role models 
available to them, yet these same BRNs considered role modelling a prerequisite for good role development. While not every organization already employs BRNs that can serve as role models for new colleagues, our findings suggest that it might be wise for organizations to start by employing at least two, since they could support each other and turn to one another for guidance (Jokiniemi et al., 2015). Moreover, a virtual learning network among BRNs working in nursing homes might help BRNs develop their role.

On a micro-level, BRNs working in nursing homes need to refine their communication skills so they can convey their affiliation with the other nurses and make clear that they are not filling a new role that is "above" that of others. Between organizations, opinions differed regarding whether BRNs should be formally part of a direct care team, or should only work together with teams as institutionallevel consultants. Based on the experiences of two organizations, our findings suggest that one BRN working with several teams might be effective in improving QoC in nursing homes. Moreover, it might not be wise to employ a BRN in each ward. If a BRN is employed to work in direct resident care on a specific ward exclusively, he or she might develop close relationships with the team members that might hinder the BRN's ability to fulfil an informal leadership role. In contrast, when working with too many teams, the time spent in any one ward would be low, potentially leading to an "out of sight, out of mind" mentality among the team members, undercutting the BRN's authority (McAiney et al., 2008).

BRNs were expected to improve QoC in two ways. They either focused on improving QoC in specific areas of expertise (e.g. residents' dementia-related behaviours) or on improving QoC in general. Both approaches were reported by participants as adding value to care practices; our findings do not suggest that one approach is more favourable than the other. Nevertheless, employing them for a specific area of expertise might make the BRN role clearer to other staff.

With regard to the perceived unique contribution of BRNs in care practice, we found discrepancies between the experiences of board- and management-level participants and those of direct care staff members. There were several potential reasons for this discrepancy. For one, board members and managers have a broader view of staff roles in their organization. In the process of implementing the BRN role, they likely considered how various staff can have an impact on resident, staff and organizational outcomes. It is possible that, during the interviews, they reflected on their ideas or expectations about the unique contribution of BRNs instead of reporting their actual experiences.

In contrast, direct care staff members were not likely reflecting on the BRNs' potential to improve QoC in general, but instead reporting their actual experiences with the BRNs. In only one organization, the direct care staff members reported that the role of the BRNs was clear and that they experienced a unique contribution of BRNs. In the organization where staff members reported that the BRNs' tasks in direct resident care did not differ from those of other staff, it might be the case that they differentiated the BRN by "a piece of paper" only. To ensure that organizations benefit from the work of BRNs, they should evaluate whether their staff members' perceptions of the BRN role align with the goals they hope to fulfil by employing BRNs (Li, Westbrook, Callen, Georgiou, \& Braithwaite, 2013). However, conducting well-planned evaluations of the effectiveness of BRNs is challenging (Donald et al., 2013). In our study, even though respondents reported that the employment of BRNs led to a decrease in physical restraint use or direct care staff absenteeism, it is possible that other factors led to these outcomes.

\section{1 | Limitations}

To our knowledge, this is the first study to explore how BRNs can be employed in nursing homes. Even though it was not our aim to provide a complete picture of all possible ways to employ BRNs, we acknowledge that the generalizability of our findings is limited due to the small sample size. To ensure quality of the analysis, four interviews were separately analysed by two members of the research team and all analyses were discussed in the research team.

\section{5 | CONCLUSION}

This exploratory, qualitative study demonstrates that there is no "gold standard" for employing BRNs in nursing homes. Instead, it presents different factors that can contribute to the development of BRN roles in nursing homes. In addition, insights are provided into why some organizations succeed in employing BRNs in nursing homes, while other organizations do not.

The findings of this study should be used to inform future research. Future studies should aim to provide more insight into the tasks BRNs are actually performing in nursing homes, either through direct observations, or having BRNs complete logs or diaries where they track their activities. To inform policy, evaluations of the effectiveness (including cost) of employing BRNs in nursing homes should be conducted. However, it might be difficult to select generic outcome variables for these analyses.

Our findings suggest that BRNs might improve QoC in nursing homes and have different implications for practice. A careful implementation and evaluation of the BRN role appears crucial for their successful employment. The steps presented in the "participatory, evidence-based, patient-focused process, for guiding the development, implementation and evaluation of advanced practice nursing" (PEPPA) framework (Bryant-Lukosius \& Dicenso, 2004) may prove useful in guiding this process.

\section{CONFLICT OF INTEREST}

No conflict of interest has been declared by the authors.

\section{AUTHOR CONTRIBUTIONS}

All authors have agreed on the final version and meet at least one of the following criteria [recommended by the ICMJE (http://www.ic mje.org/recommendations/)]: 
- substantial contributions to conception and design, acquisition of data or analysis and interpretation of data;

- drafting the article or revising it critically for important intellectual content.

\section{ORCID}

Ramona Backhaus (D) http://orcid.org/0000-0002-0817-9872

\section{REFERENCES}

Aiken, L. H., Sloane, D. M., Bruyneel, L., Van den Heede, K., Griffiths, P., \& Busse, R., ... Sermeus, W. (2014). Nurse staffing and education and hospital mortality in nine European countries: A retrospective observational study. The Lancet, 383(9931), 1824-1830.

Backhaus, R., Van Rossum, E., Verbeek, H., Halfens, R., Tan, F., Capezuti, E., \& Hamers, J. P. H. (2017). Relationship between the presence of baccalaureate-educated $\mathrm{RNs}$ and quality of care: A cross-sectional study in Dutch long-term care facilities. BMC Health Services Research, 17(53).

Backhaus, R., Verbeek, H., Van Rossum, E., Capezuti, E., \& Hamers, J. P. H. (2014). Nurse staffing impact on quality of care in nursing homes: A systematic review of longitudinal studies. Journal of the American Medical Directors Association, 15(6), 383-393.

Backhaus, R., Verbeek, H., Van Rossum, E., Capezuti, E., \& Hamers, J. P. $\mathrm{H}$. (2015). Future distinguishing competencies of baccalaureate-educated registered nurses in nursing homes. Geriatric Nursing, 36(6), 438-444.

Barbour, R. S. (2001). Checklists for improving rigour in qualitative research: A case of the tail wagging the dog? British Medical Journal, 322(7294), 1115.

Boström, A.-M., Slaughter, S. E., Chojecki, D., \& Estabrooks, C. A. (2012). What do we know about knowledge translation in the care of older adults? A scoping review. Journal of the American Medical Directors Association, 13(3), 210-219.

Bryant-Lukosius, D., \& Dicenso, A. (2004). A framework for the introduction and evaluation of advanced practice nursing roles. Journal of Advanced Nursing, 48(5), 530-540.

Donald, F., Martin-Misener, R., Carter, N., Donald, E. E., Kaasalainen, S., \& Wickson-Griffiths, A., .. DiCenso, A. (2013). A systematic review of the effectiveness of advanced practice nurses in long-term care. Journal of Advanced Nursing, 69(10), 2148-2161.

Eldh, A. C., Zijpp, T., McMullan, C., McCormack, B., Seers, K., \& RycroftMalone, J. (2015). 'I have the world's best job' - staff experience of the advantages of caring for older people. Scandinavian Journal of Caring Sciences, 30(2), 365-373.

Fougère, B., Morley, J. E., Decavel, F., Nourhashémi, F., Abele, P., Resnick, B., ... Pédra, M. (2016). Development and implementation of the advanced practice nurse worldwide with an interest in geriatric care. Journal of the American Medical Directors Association, 17(9), 782-788.

Graneheim, U. H., \& Lundman, B. (2004). Qualitative content analysis in nursing research: Concepts, procedures and measures to achieve trustworthiness. Nurse Education Today, 24(2), 105-112.

Hamers, J. P. H., Backhaus, R., Beerens, H. C., Van Rossum, E., \& Verbeek, H. (2016). Meer is niet per se beter - De relatie tussen personele inzet en kwaliteit van zorg in verpleeghuizen. Maastricht: Datawyse Universiteire Pers Maastricht.

Hsieh, H.-F., \& Shannon, S. E. (2005). Three approaches to qualitative content analysis. Qualitative Health Research, 15(9), 1277-1288.

Huizenga, P., Finnema, E., \& Roodbol, P. (2016). Learnt and perceived professional roles of a new type of nurse specialized in gerontology and geriatrics, a qualitative study. Journal of Advanced Nursing, 72(7), 1552-1566.

Huls, M., De Rooij, S. E., Diepstraten, A., Koopmans, R., \& Helmich, E. (2015). Learning to care for older patients: Hospitals and nursing homes as learning environments. Medical Education, 49(3), 332339.

Jokiniemi, K., Haatainen, K., \& Pietilä, A. M. (2015). From challenges to advanced practice registered nursing role development: Qualitative interview study. International Journal of Nursing Practice, 21(6), 896903.

Katz, P. R. (2011). An international perspective on long term care: Focus on nursing homes. Journal of the American Medical Directors Association, 12(7), 487-492.

Li, J., Westbrook, J., Callen, J., Georgiou, A., \& Braithwaite, J. (2013). The impact of nurse practitioners on care delivery in the emergency department: A multiple perspectives qualitative study. BMC Health Services Research, 13(1), 356-364.

McAiney, C. A., Haughton, D., Jennings, J., Farr, D., Hillier, L., \& Morden, P. (2008). A unique practice model for nurse practitioners in longterm care homes. Journal of Advanced Nursing, 62(5), 562-571.

McGilton, K. S., Bowers, B. J., Heath, H., Shannon, K., Dellefield, M. E., Prentice, D., ... Ploeg, J. (2016). Recommendations from the international consortium on professional nursing practice in long-term care homes. Journal of the American Medical Directors Association, 17(2), 99-103.

Phelan, A., \& McCormack, B. (2016). Exploring nursing expertise in residential care for older people: A mixed method study. Journal of Advanced Nursing, 72(10), 2524-2535.

Polit, D. F., \& Beck, C. T. (2017). Nursing research: Generating and assessing evidence for nursing practice. Philadelphia: Wolters Kluwer Health.

Sanford, A. M., Orrell, M., Tolson, D., Abbatecola, A. M., Arai, H., Bauer, J. M., ... Goel, A. (2015). An international definition for "nursing home". Journal of the American Medical Directors Association, 16(3), 181-184.

Sloane, P. D., Zimmerman, S., \& D'Souza, M. F. (2014). What will long-term care be like in 2040? North Carolina Medical Journal, 75(5), 326-330.

Spilsbury, K., Hewitt, C., Stirk, L., \& Bowman, C. (2011). The relationship between nurse staffing and quality of care in nursing homes: A systematic review. International Journal of Nursing Studies, 48(6), 732750.

Tuinman, A., De Greef, M. H., Krijnen, W. P., Nieweg, R. M., \& Roodbol, P. F. (2016). Examining time use of Dutch nursing staff in long-term institutional care: A time-motion study. Journal of the American Medical Directors Association, 17(2), 148-154.

Utens, C. M., Dirksen, C. D., Van der Weijden, T., \& Joore, M. A. (2016). How to integrate research evidence on patient preferences in pharmaceutical coverage decisions and clinical practice guidelines: A qualitative study among Dutch stakeholders. Health Policy, 120(1), 120-128.

Verkaik, R., Francke, A. L., Van Meijel, B., Spreeuwenberg, P. M. M., Ribbe, M. W., \& Bensing, J. M. (2011). The introduction of a nursing guideline on depression at psychogeriatric nursing home wards: Effects on certified nurse assistants. International Journal of Nursing Studies, 48(6), 710-719.

How to cite this article: Backhaus $\mathrm{R}$, Verbeek $\mathrm{H}$, van Rossum E, Capezuti E, Hamers JPH. Baccalaureate-educated

Registered Nurses in nursing homes: Experiences and opinions of administrators and nursing staff. J Adv Nurs. 2018;74:75-88. https://doi.org/10.1111/jan.13391 
The Journal of Advanced Nursing (JAN) is an international, peer-reviewed, scientific journal. JAN contributes to the advancement of evidencebased nursing, midwifery and health care by disseminating high quality research and scholarship of contemporary relevance and with potential to advance knowledge for practice, education, management or policy. JAN publishes research reviews, original research reports and methodological and theoretical papers.

For further information, please visit JAN on the Wiley Online Library website: www.wileyonlinelibrary.com/journal/jan

Reasons to publish your work in JAN:

- High-impact forum: the world's most cited nursing journal, with an Impact Factor of 1.998 - ranked 12/114 in the 2016 ISI Journal Citation Reports () (Nursing (Social Science)).

- Most read nursing journal in the world: over 3 million articles downloaded online per year and accessible in over 10,000 libraries worldwide (including over 3,500 in developing countries with free or low cost access).

- Fast and easy online submission: online submission at http://mc.manuscriptcentral.com/jan.

- Positive publishing experience: rapid double-blind peer review with constructive feedback.

- Rapid online publication in five weeks: average time from final manuscript arriving in production to online publication.

- Online Open: the option to pay to make your article freely and openly accessible to non-subscribers upon publication on Wiley Online Library, as well as the option to deposit the article in your own or your funding agency's preferred archive (e.g. PubMed). 